\title{
Leitura e letramento
}

Recebido em 29.04.2015. Aprovado em 05.05. 2015 Avaliado pelo sistema double blind review

\author{
Emília dos Santos Soares \\ strife22003@yahoo.com.br \\ Escola Estadual LUIZ GAMA - Araçatuba - SP - Brasil \\ Resumo
}

A possibilidade de aperfeiçoamento do trabalho pedagógico sempre existe. Acreditarmos que o estímulo ao fortalecimento da capacidade leitora e escritora poderá conduzir as pessoas a melhorarem suas condições de expressão e comunicação tanto verbal quanto escrita é apostar na evolução intelectual do ser humano.

Quando pensamos em implantação de uma sala de leitura convenientemente instalada e sob a tutela de profissionais capacitados para bem atuar, a expectativa aliada à nossa experiência, nos remete a esperar resultados promissores rumo à superação de inúmeras dificuldades que se relacionam à leitura, escrita de textos e verbalização.

0 investimento em instalações elétricas, informatização, mobiliário específico, recursos humanos, remanejamento de sala administrativa para disponibilização de espaço físico, diante dos avanços que certamente serão agregados à aprendizagem dos estudantes, se tornam perfeitamente viáveis permitindo muito mais qualidade aos serviços educacionais.

A valorização do saber cultural e acadêmico tende a repercutir num processo de transformação pessoal com substanciais transformações sócio culturais em direção a uma sociedade mais solidária, humanizada e cooperativa, uma vez que, a compreensão de diferentes fatos e fenômenos auxilia o ser humano nesta sua trajetória pela vida e a leitura constitui-se num instrumento de valiosa importância na formação cidadã.

Palavras-chaves: Educação. Oficinas educacionais. Plano de empreendimento. Laboratório de informática. 


\section{Contexto da escola}

A escola está situada muito próximo do centro da cidade, num bairro antigo possuindo uma vizinhança formada por uma população em sua maioria composta de idosos. Estes conservam um bom relacionamento com a equipe escolar e sempre cooperam observando o prédio em períodos de férias, feriados, fins de semanas, fato muito positivo pois não possuímos zelador habitando no espaço escolar.

Caracterização da Unidade Escolar:

Escola Estadual EE LUIZ GAMA

Rua: Rubião Junior $n^{0} 214$

Bairro São Joaquim

Araçatuba - São Paulo

Data da criação: 19/01/1939 - Publicado no D.O. de 19/01/1939

Data da instalação e funcionamento: 16/01/1939

A tabela 1 mostra os cursos disponibilizados à população e o horário de funcionamento dos mesmos; sendo todos muito procurados pela comunidade.

\begin{tabular}{|l|l|l|}
\hline Curso & Série / Ano & Horários de atendimento \\
\hline $\begin{array}{l}\text { Ensino Fundamental } \\
\text { Escola de Tempo Integral }\end{array}$ & $\begin{array}{l}6^{\circ} \text { ano "A" } \\
7^{0} \text { ano"A" } \\
7^{\circ} \text { ano "B" } \\
8^{\circ} \text { ano"A" } \\
9^{\circ} \text { ano"A" }\end{array}$ & 7 horas às 16 horas \\
\hline Ensino Médio & $\begin{array}{l}1^{\circ} \mathrm{A} \\
2^{\circ} \mathrm{A}\end{array}$ & 7 horas às 12horas 20minutos \\
\hline $\begin{array}{l}3^{\circ} \mathrm{A} \\
\text { Ensino Regular } \\
\text { Educação de Jovens e Adultos }\end{array}$ & $\begin{array}{l}1^{\circ} \text { Termo A } \\
2^{\circ} \text { Termo A } \\
3^{\circ} \text { Termo A } \\
4^{\circ} \text { Termo A }\end{array}$ & 19 horas às 23 horas \\
\hline
\end{tabular}

Tabela 1: Cursos e horário de atendimento/2014

\section{Breve Histórico da unidade escolar:}

A escola localiza-se neste local desde 1954, em Araçatuba, à noroeste do Estado de São Paulo, próximo à antiga Ferrovia Noroeste. Por ter sido esta um meio de comunicação entre os municípios e os estados de São Paulo e Mato Grosso do Sul, o trem que nela circulava servia para transportar passageiros e cargas de bens, produzidos aqui e em outras regiões, favorecendo a migração para esta cidade.

Os bairros Santana e São Joaquim, fazem parte da história de Araçatuba por estarem próximos à Estação Ferroviária, hoje transformada em ponto de integração dos ônibus circulares municipais de um lado, e de 
outro, o Centro Cultural de Araçatuba.

Em 1930 criava-se esta escola com o nome de $3^{\circ}$ Grupo Escolar de Araçatuba, localizada à Praça São Joaquim, $n^{0} 46$, no bairro São Joaquim, imediações da Ferrovia. Por se localizar próxima à estação Ferroviária e às casas dos ferroviários, como também do comércio formado em decorrência da estação, houve a necessidade de criar-se uma escola para atender os filhos dos ferroviários, dos comerciantes e da população desses bairros.

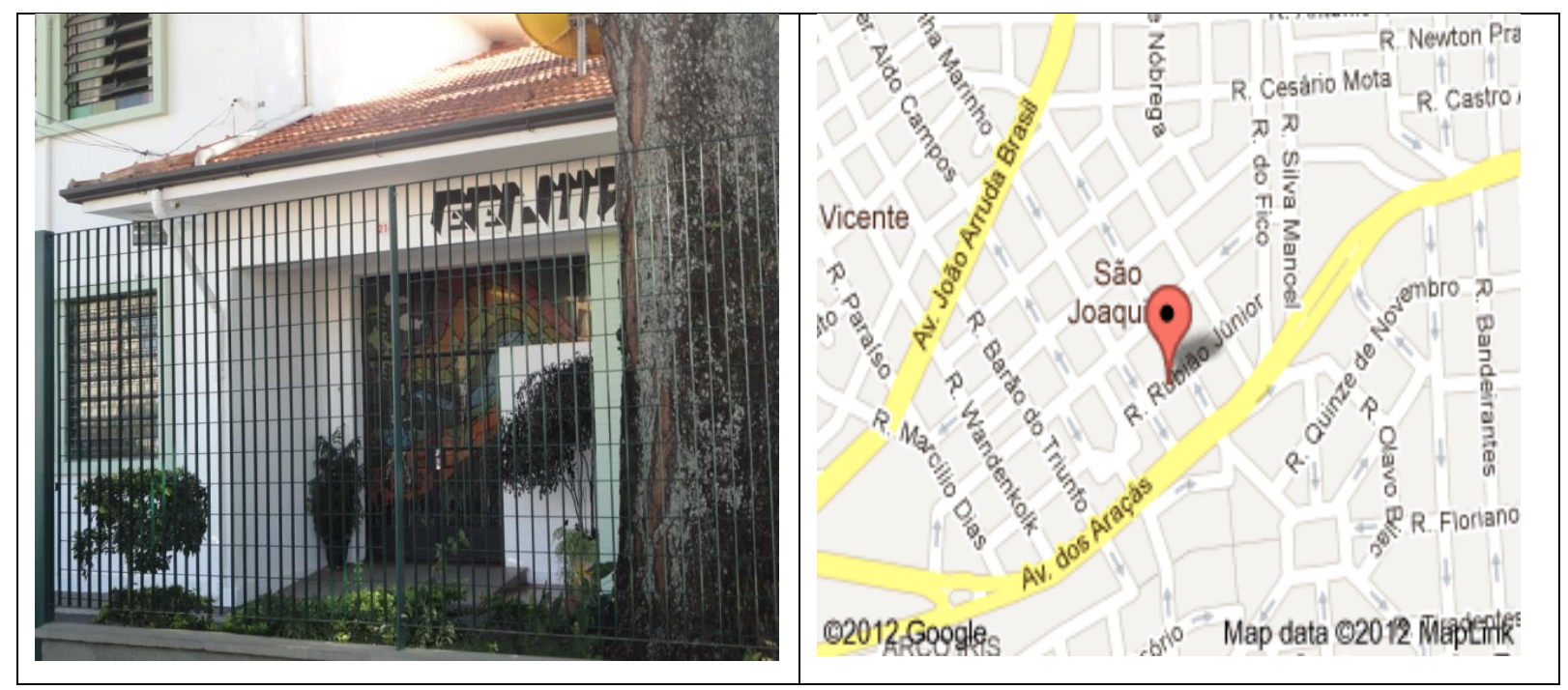

Foto: Fachada da E.E. Luiz Gama/ localização no município

No ano de 1954, o diretor desta escola, José Camilo de Andrade, observando que no bairro predominava uma população de raça negra e que as ruas levavam nomes de abolicionistas, alterou o nome desta instituição, passando a chamar-se Grupo Escolar Luiz Gama, em homenagem ao baiano Luiz Gonzaga Pinto da Gama, negro, abolicionista que participou na fundação do partido republicano paulista.

Em 1954 a construção de um novo prédio se viabilizou pela iniciativa das professoras Wanda Miranda Molina, que doou o terreno, Maria Balthazar Poço e o vereador Murilo Simão Silva, melhorando assim as instalações da escola que foi então transferida para o endereço atual.

Até 1976, o Grupo escolar Luiz Gama possuía apenas as quatro primeiras séries do Ensino Fundamental, quando foi feita a reestruturação do ensino no Estado de São Paulo atendendo todo o ciclo de $1^{\circ} \mathrm{grau}$, tornando-se uma EEPG "Luiz Gama" (Escola Estadual de Primeiro Grau), atendendo à Resolução SE 21/76, publicada em 24/01/1976.

De sua instalação até os dias atuais, o número de alunos cresceu bastante, passando a funcionar em três períodos e oferecendo o Ensino Fundamental Educação de Jovens e Adultos. No ano de 2006 foi implantado o Ensino Médio e a Escola de Tempo Integral com nove horas de duração.

A escola surgiu em uma década onde ocorreram mudanças substanciais na educação do país predominando uma visão da educação como instrumento de democratização e equalização social.

Atualmente temos por missão a busca por um ensino de qualidade, garantindo o acesso e permanência dos alunos, formando cidadãos críticos e participantes, capazes de agir para transformar a sociedade rumo ao desenvolvimento sustentável e humanização das relações interpessoais.

Nossa visão de futuro consiste em ter o reconhecimento da comunidade escolar como sendo uma unidade de ensino pública prestadora de serviços educacionais indispensáveis à formação dos cidadãos. 


\section{Perfil dos alunos e professores:}

A atual E. E. Luiz Gama atende cerca de 400 alunos com faixa etária de 11 a 14 anos cursando o ensino fundamental em tempo integral, 15 a 17 anos no ensino médio regular e pessoas de 15 a 70 anos na Educação de Jovens e Adultos ciclo II.

Hoje, a clientela em sua maioria já não reside mais no bairro onde a escola está instalada. Recebemos alunos de vários pontos da cidade. Sua localização é na região central da urbe e muito próxima do terminal de integração dos ônibus circulares municipais o que facilita o deslocamento dos alunos.

A Escola Municipal Francisca Fernandes encaminha os alunos concluintes do ciclo I para esta unidade conforme determina o planejamento no que tange às áreas de abrangência, onde iniciam o ciclo II. Já os alunos que cursam a Educação de Jovens e Adultos deslocam-se das periferias da cidade e da zona rural.

A escola além das reuniões bimestrais, sempre convida os responsáveis para comparecerem e cooperarem na resolução de dificuldades que surgem no cotidiano, assim sendo, nossas Atpc(s) contam com a participação dos pais, fato que tem promovido o estreitamento de nossas relações com a comunidade.

A Escola de Tempo Integral possui uma forte procura de atendimento à demanda composta por alunos, cujos responsáveis demonstram tranqüilidade em saber que seus filhos estão bem atendidos o dia inteiro e com a alimentação assegurada, pois, não dispõem de condições para estarem mais próximos no dia a dia. Os alunos por sua vez, em sua maioria, são empenhados e demonstram interesse em prosseguimento dos estudos.

Trabalham nesta escola 27 professores, sendo 15 titulares de cargo efetivos e 12 ocupantes de função atividade, todos profissionais com o ensino superior completo, cinco deles cursam pós-graduação lato sensu, dois cursam mestrado e os demais possuem licenciatura plena, atuando num regime de até 32 aulas semanais. Caracterizam-se pelo comprometimento com a profissão o que tem repercutido positivamente no aproveitamento dos nossos estudantes.

\section{Características mais marcantes do local onde a escola se insere:}

A escola está situada próximo à região central da cidade favorecendo parcerias com alguns locais como centro comercial, praça pública, zoológico municipal, ginásio de esportes e museu. Araçatuba, localizada no noroeste paulista, possui cerca de 180 mil habitantes, é um grande centro regional estudantil, possuindo quatro universidades: Três particulares e uma estadual, uma fundação e demais faculdades particulares. É um grande pólo formador de mão-de-obra especializada, abrigando estudantes de todo o Brasil e ascendendo no mercado imobiliário. Possui uma das menores taxas de analfabetismo da população adulta entre as cidades-sede de região administrativa do Oeste Paulista.

Funcionam também em Araçatuba escolas profissionalizantes como o SENAI, o SENAC e SESI.

Considerando que nossa região tem sua economia apoiada na agroindústria açucareira constatamos que os nossos alunos são oriundos de classes populares: trabalhadores braçais da lavoura canavieira, comerciários, diaristas, operários da construção civil, etc. Compreendem que o crescimento econômico no Brasil requer qualificação de seus cidadãos e vêem na escola uma oportunidade de melhorar suas vidas investindo no seu aperfeiçoamento rumo à inserção cada vez mais qualificada no mercado de trabalho.

\section{Identificação do problema ou da oportunidade}

O problema que a escola enfrenta relaciona-se às expectativas de se atingir e ultrapassar as metas propostas pela Secretaria de Estado da Educação, considerando que estas retratam a qualidade do serviço educacional prestado pela escola em cada ciclo.

Observando a série histórica desta última década observo um ir e vir nos nossos resultados, conforme demonstra a tabela 2 que se segue: 


\begin{tabular}{|c|c|c|c|c|c|c|c|c|c|c|c|c|c|c|}
\hline & $\begin{array}{l}\text { IDES } \\
P \\
2007\end{array}$ & $\begin{array}{l}\text { METAS } \\
2008\end{array}$ & \begin{tabular}{|l} 
IDES \\
$P$ \\
2008
\end{tabular} & $\begin{array}{l}\text { METAS } \\
2009\end{array}$ & \begin{tabular}{|l} 
IDES \\
$P$ \\
2009
\end{tabular} & $\begin{array}{l}\text { METAS } \\
2010\end{array}$ & \begin{tabular}{|l} 
IDES \\
$P$ \\
2010
\end{tabular} & $\begin{array}{l}\text { METAS } \\
2011\end{array}$ & \begin{tabular}{|l} 
IDES \\
$P$ \\
2011
\end{tabular} & $\begin{array}{l}\text { METAS } \\
2012\end{array}$ & $\begin{array}{l}\text { IDES } \\
\text { P } \\
2012\end{array}$ & $\begin{array}{l}\text { METAS } \\
2013\end{array}$ & $\begin{array}{l}\text { IDES } \\
P \\
2013\end{array}$ & $\begin{array}{l}\text { METAS } \\
2014\end{array}$ \\
\hline$F$ & 3,6 & 3,7 & \begin{tabular}{|l}
3,39 \\
\end{tabular} & 3,5 & 3,68 & 3,79 & 3,23 & 3,41 & 3,6 & 3,77 & 3,25 & 3,37 & 3,94 & 4,06 \\
\hline M & 0 & 0 & 1,75 & 1,86 & 2,21 & 2,32 & 2,56 & 2,75 & 2,86 & 3,05 & 2,59 & 2,69 & 2,92 & 3,03 \\
\hline
\end{tabular}

Tabela 2: Evolução dos indicadores 2007 a 2013 ( $F=$ ensino fundamental e $M=$ ensino médio)

Tal fato, aliado aos resultados apresentados pela avaliação da aprendizagem em processo, nos remete a pensar que a capacidade leitora e escritora de nossos estudantes necessitam de especial atenção, pois, somente com o estímulo ao gosto pela leitura, com vistas à ultrapassar a leitura do código escrito e contribuindo com a evolução da aprendizagem conseguiremos ampliar a capacidade interpretativa instrumentalizando-os para a concretização dos avanços esperados.

Expressar-se com clareza é uma das dificuldades de quem precisa redigir um texto. A leitura atenta de bons textos pode ajudar a desenvolver a capacidade leitora, escritora e interpretativa. Ninguém chega à escrita sem antes ter passado pela leitura. Quem tem o hábito de leitura é capaz de escrever sem muita dificuldade. A leitura eficiente de livros, revistas e jornais permitem-nos refletir sobre idéias e formular nossa própria opinião.

É necessário, também, o domínio de alguns recursos lingüísticos básicos, aliados a uma postura crítica sobre a realidade para aprimorar a qualidade do texto.

Ao analisarmos uma avaliação diagnóstica aplicada logo no primeiro bimestre deste ano letivo selecionamos as questões onde ocorreu o maior número de erros e depois de efetuado o levantamento das habilidades que estas avaliavam apurou-se que as dificuldades apontadas nas questões se referem às habilidades de procedimentos básicos de leitura: Localizar informações explícitas com base na compreensão geral de um texto, inferir informações implícitas (conceitos, opiniões, tema, assunto principal de um texto, distinção entre um fato e uma opinião relativa a esse fato e identificar os fatos de um texto em seqüência lógica).

Estas habilidades que precisam ser adquiridas por nossos alunos podem ser desenvolvidas por meio da prática de leitura, pois 0 acesso aos livros de diferentes gêneros literários favorece a apropriação dessas capacidades cognitivas.

Diante dos fatos diagnosticados, com o intuito de resolver este problema, o projeto salutar para operacionalizarmos um plano de empreendimento será a implantação de uma sala de leitura, bem instalada, com um bom mobiliário e acervo literário sob a tutela de professores especialistas em língua portuguesa atuando nos três períodos de funcionamento da escola, oferecendo um suporte aos demais docentes no sentido de superação das dificuldades rumo à melhoria da aprendizagem, incluindo o envolvimento dos pais nos projetos de leitura; detectando nesta comunidade potenciais contadores de histórias para apresentações motivadoras periódicas. Além da publicação do jornal "Noticiário Luiz Gama" com a participação de todas as turmas.

Segue a tabela 3 com o boletim da escola IDESP, cujos indicadores confirmam a realidade que estamos observando, pois o número de estudantes com desempenho abaixo do básico, é considerável e requer direcionamento de ações pedagógicas.Trata-se do boletim IDESP com o resultado da E.E. Luiz Gama publicado pela Secretaria de Estado da Educação.

Demonstrando-nos que, mesmo atingindo as metas propostas há necessidade de aperfeiçoamento dos trabalhos. 
IDESP 2013 - Distribuição por Níveis de Desempenho

\begin{tabular}{|l|l|l|l|l|l|}
\cline { 3 - 6 } \multicolumn{2}{c|}{} & Abaixo do Básico & Básico & Adequado & Avançado \\
\hline $9^{\circ}$ ano EF & Língua portuguesa & 0,1875 & 0,5313 & 0,2188 & 0,0625 \\
\cline { 2 - 6 } & Matemática & 0,1563 & 0,5625 & 0,1875 & 0,0938 \\
\hline \multirow{3}{*}{$3^{\text {a }}$ série EM } & Língua Portuguesa & 0,1923 & 0,4615 & 0,3462 & 0 \\
\cline { 2 - 6 } & Matemática & 0,4231 & 0,5 & 0,0769 & 0 \\
\hline
\end{tabular}

Tabela 3: Boletim IDESP da E. E. LUIZ GAMA

Índice de Cumprimento de Metas por Ciclo Escolar:

\begin{tabular}{|l|l|l|l|}
\cline { 2 - 4 } \multicolumn{1}{c|}{} & Máximo & Índice de Nível Socioeconômico & Índice de Cumprimento de Metas \\
\hline $9^{\circ}$ ano EF & 120 & 3,39 & 120 \\
\hline $3^{\text {a }}$ série EM & 120 & 3,39 & 120 \\
\hline
\end{tabular}

${ }^{*} O$ índice de cumprimento de metas se limita a 120

${ }^{*}$ O valor atribuído ao modular (MOD) é igual a $10 \%(0,10)$

Índice de Cumprimento de Metas 2013 da Escola:

\begin{tabular}{|l|l|l|l|}
\cline { 2 - 3 } \multicolumn{1}{c|}{} & $N^{0}$ de Alunos & Proporção de alunos avaliados (\%) & $\begin{array}{l}\text { Índice de Cumprimento } \\
\text { de Metas da Escola }\end{array}$ \\
\hline $9^{0}$ ano EF & 32 & $55,17 \%$ & \multirow{2}{*}{120} \\
\hline $3^{\text {a }}$ série EM & 26 & $44,83 \%$ & \\
\hline Total & 58 & $100 \%$ & \\
\hline
\end{tabular}

Metas 2013 por Ciclo Escolar:

\begin{tabular}{|l|l|l|}
\cline { 2 - 3 } \multicolumn{1}{c|}{} & IDESP 2013 & Metas 2014 \\
\hline $9^{\circ}$ ano EF & 3,94 & 4,06 \\
\hline $3^{\text {a }}$ série EM & 2,92 & 3,03 \\
\hline
\end{tabular}

Fonte: Secretaria de Estado da Educação do Estado de São Paulo

\section{Caracterização do Produto/Serviço Ou Processo}

Ao propor a implantação de uma sala específica para leitura é interessante explicitar que todos os alunos e demais membros dessa comunidade serão diretamente beneficiados. Embora nem todos residam nas proximidades da escola, o tempo de deslocamento é breve, uma vez que, utilizam veículos automotores como meio de transporte e as ruas e avenidas permitem o percurso sem congestionamentos.

A idade média de nossos alunos dos cursos diurnos varia de 11 a 17 anos; enquanto que, no curso noturno variam de 15 a 70 anos; estes provêm de famílias que, em sua maioria possuem como nível educacional o ensino fundamental completo, nem todos são familiarizados com as novas tecnologias, porém são receptíveis às novas idéias, projetos e têm como atividades sociais nos feriados e finais de semana a freqüência às 
igrejas (evangélicos, católicos e espíritas) sendo que, muitos deles cultivam alguns gêneros de leitura como passatempo.

Conscientes de que o ensino da leitura e da escrita é uma contribuição para que todos possam aprender na escola e também fora dela e também que enquanto educadores que somos sempre podemos aperfeiçoar os serviços que prestamos, considero relevante citar parte do artigo de Marta Durante e Miriam Orensztejn quando explicam que

“... durante um longo tempo em nosso país, acreditou-se que seria suficiente ensinar aos alunos as letras, as sílabas, as palavras, a escrita com letra cursiva e que depois, sozinhos, eles teriam condições de ler e escrever todos os gêneros textuais e, assim, continuar aprendendo dentro e fora da escola. Podemos verificar o fracasso dessa concepção não só na quantidade de não alfabetizados, como na de analfabetos funcionais (adultos que dominam o sistema de escrita, mas que não conseguem utilizar a leitura e a escrita com sua real função de uso) que o sistema gerou, mas também naqueles que teoricamente não fracassaram, já que conseguiram continuar estudando. Muitas vezes, mesmo freqüentando faculdades ou centros universitários e embora tenham passado no mínimo onze anos nas escolas de ensino fundamental e médio, esses alunos apresentam dificuldades básicas em relação à leitura e à escrita de textos."

Os dados que se seguem constam da Pesquisa Nacional por Amostra de Domicílios (Pnad) 2012, divulgada pelo Instituto Brasileiro de Geografia e Estatística (IBGE).

O analfabetismo cresceu no Brasil em 2012. O contingente de pessoas que não sabem ler nem escrever chegou a 13,2 milhões de pessoas, o equivalente a $8,7 \%$ da população residente no país.

Em 2011, segundo o IBGE, o analfabetismo atingia 8,6\% da população residente no país, 12,9 milhões de pessoas.

A taxa de analfabetismo funcional foi estimada em 18,3\%, o equivalente a 27,8 milhões de pessoas. Em 2011, a taxa era de 20,4\%. No sudeste, o analfabetismo manteve-se estável em 4,8\% em 2012 na comparação com 0 ano anterior.

A tabela que segue aponta aspectos da população de Araçatuba deixando claro que o número de analfabetos residentes na cidade é de aproximadamente 18225 habitantes.

\begin{tabular}{|l|l|l|}
\hline Área da unidade territorial & $1.167,438$ & $\mathrm{~km}^{2}$ \\
\hline \hline Índice de Desenvolvimento Humano Municipal - 2010 (IDHM 2010) & 0,788 & \\
\hline \hline Matrícula - Ensino fundamental - 2012 & 21.627 & matrículas \\
\hline \hline Matrícula - Ensino médio - 2012 & 7.396 & matrículas \\
\hline \hline Número de unidades locais & 6.186 & unidades \\
\hline \hline Pessoal ocupado total & 60.698 & pessoas \\
\hline \hline PIB per capita a preços correntes - 2011 & $21.374,88$ & reais \\
\hline \hline População residente & 181.579 & pessoas \\
\hline
\end{tabular}




\section{Leitura e letramento}

\begin{tabular}{|l||l||l|}
\hline População residente - Homens & 87.329 & pessoas \\
\hline \hline População residente - Mulheres & 94.250 & pessoas \\
\hline \hline População residente alfabetizada & 163.354 & pessoas \\
\hline \hline População residente que frequenta creche ou escola & 50.271 & pessoas \\
\hline \hline População residente, religião católica apostólica romana & 98.645 & pessoas \\
\hline \hline População residente, religião espirita & 6.110 & pessoas \\
\hline \hline População residente, religião evangélicas & 53.112 & pessoas \\
\hline
\end{tabular}

Tabela 4: População de Araçatuba-SP

Fonte: IBGE - Instituto Brasileiro de Geografia e Estatística

Pensando, de um modo geral, na qualidade dos serviços que esta instituição de ensino oferece e conscientes de que ensinar ler e escrever para aprender a aprender não se limita apenas a textos informativos científicos, faz-se necessário salientarmos a importância dos diferentes gêneros textuais como poemas, contos, artigos, romances e outros, sempre com o propósito de fortalecimento da aprendizagem da leitura e da escrita com autonomia para a busca de informações e conhecimentos.

O corpo docente, com base na avaliação da aprendizagem em processo, declara que nossos estudantes apresentam dificuldades em ler e compreender os textos de maior complexidade, assim sendo, o projeto consiste em preparar a escola para ensinar aos alunos procedimentos que concretize em maior autonomia para a aprendizagem. Daí o plano de empreendimento propondo a Sala de Leitura direcionada a todos nossos alunos e seus responsáveis com finalidade educativa rumo à expansão cultural.

No que se refere à freqüência de utilização pelo público alvo a construção de um quadro para agendamento semanal da sala constando a série que fará uso desse ambiente, o horário e o professor responsável nos permitirá um trabalho produtivo e organizado recorrendo ao acervo disponível. Quanto ao estilo de funcionamento podemos prever empréstimos das obras literárias tanto para os alunos como para seus familiares, com registro em livro de controle constando data de retirada, data de pedido de prorrogação de prazo se for o caso, e de devolução do material.

Todas as disciplinas envolver-se-ão no projeto, uma vez que, as possibilidades de trabalho pedagógico são diversas:

*Estimulando os alunos a ler e produzir textos;

${ }^{*}$ Socializando os textos em salas de aulas;

* Estudo dirigido com vistas a compreender e interpretar a mensagem contida em cada obra, por meio de atividades de produção textual;

*Produzir momentos de debates entre os alunos;

*Propondo dramatizações, mímicas, expressões faciais e entonação da voz, postura;

*Analisando o conflito, os valores apresentados e o final da história;

${ }^{*}$ Criação de novos finais para contos, oportunizando a criatividade dos leitores;

*Levantamento das características dos diferentes personagens.

Para a continuidade e evolução do projeto será necessário empreender esforços constantes no sentido de 
manutenção de um ambiente limpo, organizado, agradável de permanecer além de estar sempre ampliando o acervo solicitando novas obras tanto ao poder público, como junto à própria comunidade, realizações estas que, ocorrerão por meio da observação direta dos gestores do projeto e contato com os professores coordenadores do núcleo pedagógico da diretoria regional de ensino do município também bons orientadores em favor do funcionamento eficaz das salas de leitura.

Quanto aos recursos humanos necessários para o sucesso desse projeto será importante cuidarmos de duas situações:

No que tange à organização do mesmo será preciso a disponibilização de dois funcionários do quadro de serviços escolares para higienização do ambiente e mobiliários, colocação do acervo nos seus devidos lugares estando estes sob a orientação de um docente com experiência em organização bibliotecária para organização do acervo por gêneros de leituras e faixas etárias recomendadas.

No que tange à manutenção do mesmo reportam-se à necessidade da presença de dois docentes habilitados, preferencialmente em língua portuguesa com disponibilidade para atuação durante oito horas diárias cada um, fato que, assegura cobertura de atendimento em todos os horários de funcionamento da escola.

A partir do momento em que a sala de leitura estiver apropriada para utilização oportuno será convidar a comunidade escolar para participação em uma palestra, momento em que, deverá ser exposto as finalidades do ambiente específico para leitura, a possibilidade do trabalho envolvendo todas as disciplinas da grade curricular dos cursos que oferecemos, o benefício intelectual que favorecerá a todos os usuários de todas as séries. Também explicitar as perspectivas de evolução do projeto, ou seja, o direcionamento de esforços no sentido de manter 0 acervo literário atualizado, num espaço onde se procura e se produz conhecimentos melhorando a compreensão, a interpretação de textos e consequentemente a qualidade do ensino favorecendo pessoas numa convivência onde todos aprendem.

\section{Estratégias de implementação}

Trabalhando sempre em equipe, delegando responsabilidades quando se fizer necessário, informando a todos os objetivos e o andamento da implementação do projeto será uma estratégia de implementação com vistas a conseguir cooperação e comprometimento dos diferentes segmentos preparando as pessoas para a boa convivência com as mudanças que virão como uma nova oportunidade e possibilidade para a instituição de ensino.

Com o objetivo de potencializar a competência leitora e escritora fortalecendo a autonomia da aprendizagem dos nossos estudantes além de capacitá-los a produzirem textos contendo informações relativas às diversas áreas do conhecimento este plano de empreendimento apresenta o diagnóstico que se segue conforme análise SWOT.

\begin{tabular}{|l|l|l|l|}
\hline Forças & Fraquezas & Oportunidades & Ameaças \\
\hline $\begin{array}{l}\text { A Unidade escolar possui } \\
\text { um considerável acervo } \\
\text { de obras literárias. }\end{array}$ & $\begin{array}{l}\text { Não temos o mobiliário } \\
\text { adequado para a } \\
\text { organização do acervo e } \\
\text { acomodação } \\
\text { usuários. }\end{array}$ & $\begin{array}{l}\text { Podemos inscrever a } \\
\text { unidade escolar junto à } \\
\text { Secretaria de Educação } \\
\text { para requisitar a sala de } \\
\text { leitura. }\end{array}$ & $\begin{array}{l}\text { A lentidão para se } \\
\text { concretizar o processo de } \\
\text { criação da sala de leitura. }\end{array}$ \\
\hline $\begin{array}{l}\text { A Unidade escolar dispõe } \\
\text { de um espaço apropriado } \\
\text { para a instalação da sala } \\
\text { de leitura. }\end{array}$ & $\begin{array}{l}\text { No espaço está instalada } \\
\text { secretaria, a qual } \\
\text { precisa ser deslocada. }\end{array}$ & $\begin{array}{l}\text { Remanejamento da } \\
\text { secretaria e instalações } \\
\text { administrativas para outra } \\
\text { sala disponível na unidade } \\
\text { escolar. }\end{array}$ & $\begin{array}{l}\text { Conseguir autorização e } \\
\text { mão-de-obra } \\
\text { especializada } \\
\text { proceder as mudanças } \\
\text { estruturais. }\end{array}$ \\
\hline $\begin{array}{l}\text { A comunidade tem umara } \\
\text { imagem positiva da escola } \\
\text { e maioria de nossos } \\
\text { alunos possuem o hábito } \\
\text { de leitura. }\end{array}$ & $\begin{array}{l}\text { Não temos um } \\
\text { bibliotecário na unidade } \\
\text { escolar. }\end{array}$ & $\begin{array}{l}\text { A unidade escolar conta } \\
\text { com professora } \\
\text { readaptada, habilitada em } \\
\text { língua portuguesa que } \\
\text { poderá atuar na sala. }\end{array}$ & $\begin{array}{l}\text { Dificuldade de contratação } \\
\text { de mais um docente com } \\
\text { perfil apropriado } \\
\text { atuação na sala de leitura. }\end{array}$ \\
\end{tabular}




\section{Leitura e letramento}

Tabela 5: Análise SWOT

Compreendendo as metas como desafios, índices, posições para serem alcançados em um certo período de tempo para medi-las tomaremos como referência a comparação com períodos que antecedem a implementação do plano.

Analisando livros de registros, resultados de avaliações em processo e constatando as transformações que forem observadas especialmente quanto aos índices de satisfação dos usuários e o desempenho destes nas atividades em salas de aulas. Recorrer à coleta de dados poderá ser um meio para mensuração do desempenho. A tabela que se segue explicita a definição das estratégias.

\begin{tabular}{|c|c|c|}
\hline \multicolumn{3}{|c|}{ Definição das Estratégias } \\
\hline OBJETIVOS & METAS & ESTRATÉGIAS \\
\hline $\begin{array}{l}\text { Aperfeiçoar as competências leitora } \\
\text { e escritora. }\end{array}$ & $\begin{array}{l}\text { Melhorar em } 80 \% \text { de nosso público } \\
\text { alvo a capacidade de expressão e } \\
\text { comunicação. }\end{array}$ & $\begin{array}{l}\text { Identificar fatores dificultadores; } \\
\text { disponibilizar um docente para } \\
\text { orientação de estudos e pesquisas; } \\
\text { estimular a leitura, a dramatização e } \\
\text { os debates. }\end{array}$ \\
\hline Capacitar para produção de textos. & $\begin{array}{l}\text { Aperfeiçoar em } 100 \% \text { de nosso } \\
\text { público alvo a qualidade de } \\
\text { produção textual. }\end{array}$ & $\begin{array}{l}\text { Propor a reescrita; solicitar a criação } \\
\text { de outro final para os contos e ou } \\
\text { romances; orientar técnicas de } \\
\text { redação. }\end{array}$ \\
\hline $\begin{array}{l}\text { Fortalecimento da autonomia na } \\
\text { aprendizagem. }\end{array}$ & $\begin{array}{l}\text { Melhorar em } 100 \% \text { de nosso público } \\
\text { alvo a capacidade de interpretação. }\end{array}$ & $\begin{array}{l}\text { Estimular } 0 \text { interesse dos } \\
\text { estudantes; realizar saraus literários } \\
\text { e seções de contadores de histórias } \\
\text { entre os próprios estudantes; } \\
\text { reforçar a relação do aluno com as } \\
\text { obras literárias por meio de } \\
\text { atividades que aguçam a } \\
\text { curiosidade. }\end{array}$ \\
\hline
\end{tabular}

Tabela 6: Definição das estratégias

Segue um plano de ação recomendado para as principais ações definidas nas estratégias supracitadas.

\begin{tabular}{|l|l|l|}
\hline 5W2H & Pergunta & Especificando ou Definindo \\
\hline What? & O que? & $\begin{array}{l}\text { *Leitura de diferentes gêneros literários: Crônicas, fábulas, poemas, contos e } \\
\text { entrevistas. } \\
\text { *Produção de textos para inferir o sentido das palavras, contextualizar } \\
\text { historicamente e formular opinião. }\end{array}$ \\
\hline Who? & Quem? & $\begin{array}{l}\text { *Serão responsáveis os docentes da área de comunicação e expressão sob a } \\
\text { liderança do professor de língua portuguesa. } \\
\text { *Professor coordenador pedagógico. }\end{array}$ \\
\hline Where? & Onde? & "Na sala de leitura e também nas salas de aulas. \\
\hline When? & Quando? & "Nos dois anos letivos próximos vindouros. \\
\hline Why? & Por quê? & $\begin{array}{l}\text { *Para estimular o gosto pela leitura, com vistas a ultrapassar a leitura do código } \\
\text { escrito e contribuir na formação de sujeitos que possam interagir no meio social } \\
\text { com suas competências leitora, escritora e capacidade de comunicação e } \\
\text { expressão ampliadas. }\end{array}$ \\
\hline How? & Como? & \begin{tabular}{l} 
*Estudo dirigido \\
\hline
\end{tabular} \\
\hline
\end{tabular}




\begin{tabular}{|l|l|l|}
\hline & & $\begin{array}{l}\text { *Debates e dramatizações } \\
\text { *Saraus literários } \\
\end{array}$ \\
& & $\begin{array}{l}\text { *Concursos de redação } \\
\text { *Jornal mural }\end{array}$ \\
\hline How Much? & Quanto? & "Estimativa de $\mathrm{R} \$ 40000,00$ \\
\hline
\end{tabular}

Tabela7: Plano de Atividades $\rightarrow$ para as principais ações definidas nas estratégias

Ao longo do desenvolvimento do projeto será necessário o acompanhamento dos resultados e para tanto proceder-se-á como segue:

Fixar nos murais e locais visíveis por todos os objetivos pretendidos, uma vez que, todos são responsáveis pelos resultados.

Tabular informações e expor em forma de tabelas e gráficos, constando por exemplo a quantidade de livros emprestados atual e após a implementação do projeto, o número de usuários da sala de leitura, e outros.

Monitorar todo o projeto para verificar sua eficácia e se as adequações ao longo da implantação do mesmo estão produzindo os resultados almejados; ou ainda se está em processo uma melhoria contínua e motivadora dos leitores por meio da observação direta dos professores. Na tabela seguinte constam os recursos que são necessários para a boa ambiência da sala de leitura.

\begin{tabular}{|c|c|c|}
\hline O que vou precisar & Descrição & Como obter \\
\hline $\begin{array}{l}\text { Um computador, } \\
\text { impressora e mobiliário. }\end{array}$ & $\begin{array}{l}\text { Estes itens permitirão catalogar o } \\
\text { acervo, controlar os empréstimos } \\
\text { (saída e retorno) das obras e } \\
\text { também a acomodação adequada } \\
\text { de todos os usuários. }\end{array}$ & $\begin{array}{l}\text { Requisitando junto à Secretaria } \\
\text { Estadual de Educação através da } \\
\text { Diretoria Regional de Ensino. }\end{array}$ \\
\hline Acervo/ obras literárias. & $\begin{array}{l}\text { Far-se-á necessário a ampliação do } \\
\text { acervo existente agregando obras } \\
\text { literárias destinadas às diferentes } \\
\text { faixas etárias que a escola atende. }\end{array}$ & $\begin{array}{l}\text { Requisitando por meio do Professor } \\
\text { Coordenador do núcleo Pedagógico } \\
\text { - diretoria de Ensino a atualização } \\
\text { do acervo; divulgando junto à } \\
\text { comunidade que a sala de leitura } \\
\text { receberá obras literárias de } \\
\text { possíveis doadores, desde que } \\
\text { estas estejam em boas condições } \\
\text { de uso. }\end{array}$ \\
\hline $\begin{array}{l}\text { Dois bibliotecários ou docentes } \\
\text { para atuar na sala de leitura. }\end{array}$ & $\begin{array}{l}\text { Recursos humanos, cujo trabalho } \\
\text { consistirá na manutenção do acervo } \\
\text { e atendimento aos usuários nos três } \\
\text { turnos de funcionamento da unidade } \\
\text { escolar. }\end{array}$ & $\begin{array}{l}\text { Uma vez criada a sala de leitura os } \\
\text { recursos humanos se darão por } \\
\text { meio de um processo de atribuição } \\
\text { de função em conformidade com a } \\
\text { legislação em vigor. }\end{array}$ \\
\hline
\end{tabular}

Tabela 8: Recursos Necessários

\section{Marketing e comunicação}

Considerando que esta unidade escolar vem historicamente se empenhando no sentido de prestar serviços educacionais de qualidade e que sejam do interesse da comunidade na qual está inserida, sempre com 0 intuito de fortalecer as relações de confiabilidade entre a escola e nossos clientes /usuários propomos a 
criação de uma sala de leitura com boas perspectivas para que nossos usuários possam se envolver ativamente no seu processo de aprendizagem e os nossos clientes (pais) os auxiliem.

Para tanto estabelecemos como estratégia de marketing e comunicação:

Reunião, com convocação prévia, para professores, funcionários e equipe gestora, opinarem e debaterem oralmente deixando explícito a intenção de criação da sala de leitura, as mudanças necessárias para instalação, os objetivos e a importância do comprometimento dos responsáveis e da cooperação de todos para o sucesso do projeto, com vistas à um marketing integrado.

Proceder à ampla divulgação das metas propostas para esta escola pelo IDESP para o ano letivo de 2014, utilizando os murais que estrategicamente estão em locais de ampla visibilidade, destacando que, 0 aperfeiçoamento de nossos leitores poderá contribuir para atingi-las.

Oficiar os órgãos superiores, cujo aval será indispensável para a implementação do projeto, sobre a demanda latente que a escola apresenta e as metas IDESP que estamos empenhados em atingi-las, para que estes nos dêem o apoio necessário rumo ao desenvolvimento e concretização da Sala de leitura, aliado ao treinamento e capacitação em serviço das pessoas que atuarão para motivá-las, auxiliá-las e qualificá-las cada vez mais na prestação do serviço.

Serviço este que, por sua vez, especifica-se por agregar qualidade à realidade escolar melhorando o trabalho que atualmente vem sendo desenvolvido, constituindo-se numa nova oportunidade para que esta instituição de ensino possa melhor atender seus usuários e clientes e atingir melhores resultados de aprendizagem.

Ao promover a comunicação com o público alvo será de grande importância um esforço de planejamento para emitir a mensagem com muita clareza e cuidado para não ocorrer ruído na transmissão, seja no cartaz para mural da escola, seja nas convocações para reuniões, pautas ou mesmo numa circular faz-se muito necessário formulá-la corretamente para evitar que sejamos mal compreendidos balizando a comunicação com objetivo, ligação, idéia central, pontos poderosos e utilidade.

Lembrando que, neste ano letivo, realizamos uma pesquisa de marketing, a qual forneceu a esta equipe gestora informações que mostraram um diagnóstico que aponta para a necessidade de revisão do serviço da sala de leitura. Pesquisa esta que foi tipo descritiva objetivando identificar o nível de satisfação dos clientes/usuários com os serviços oferecidos pela escola e utilizamos como instrumento de coleta de dados um questionário aplicado por amostragem probabilística escolhendo por sorteio os participantes. Os principais resultados, após analisar os dados colhidos por meio do questionário em que as 88 pessoas previstas inicialmente responderam, apontaram que tanto no universo usuário como no dos clientes o índice de insatisfação mais expressivo refere-se à biblioteca da escola, único item apontado como ruim por alguns dos pesquisados e com uma considerável incidência como regular. Ao verificar quais fatores que causam insatisfação na biblioteca constatamos ser o diminuto espaço físico $\left(11 \mathrm{~m}^{2}\right)$. Embora cuidadosamente organizada não há espaço suficiente para os leitores estarem bem instalados em tão pequena dimensão. 0 acervo é divulgado e os leitores levam para casa como empréstimos para leitura. Porém a pesquisa deixou claro que anseiam por um espaço mais amplo para a instalação de uma sala de leitura, com melhor mobiliário e espaço para circulação.

No quesito instalações foi possível constatar que os optantes como regular estavam também se referindo à metragem da biblioteca. Seguem os gráficos com a tabulação das respostas dos estudantes e posteriormente a tabulação das respostas dos pais. 


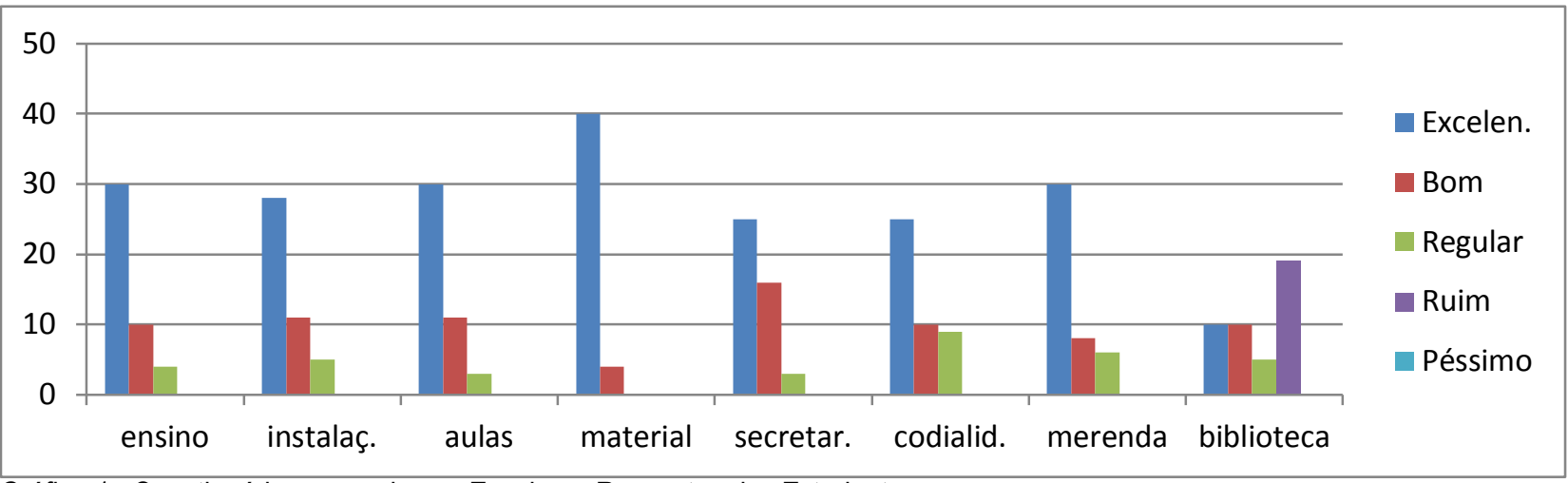

Gráfico 1: Questionário - pesquisa na Escola Respostas dos Estudantes

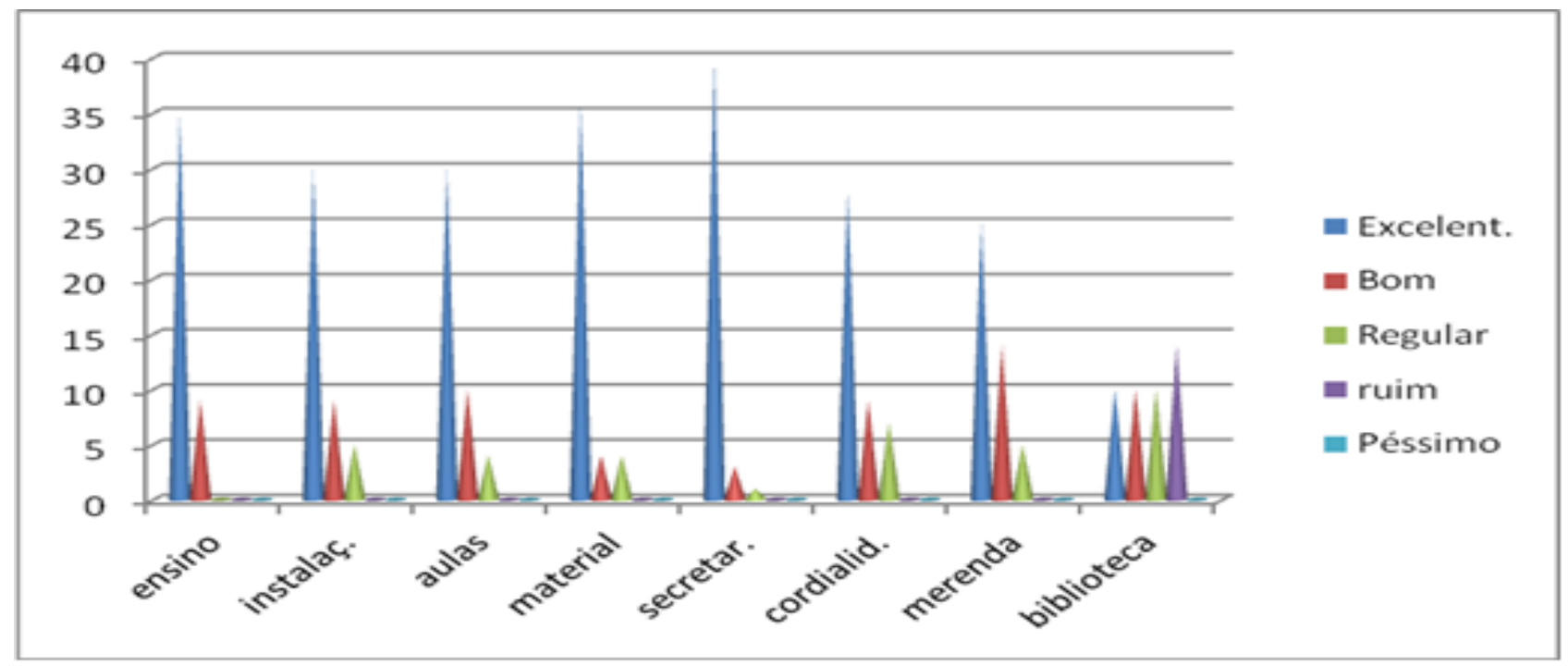

Gráfico 2: Questionário - pesquisa na Escola Respostas dos Pais

Diante dos resultados obtidos apura-se a necessidade das ações que se seguem:

Considerando que é fato, é realidade, a biblioteca funciona em um espaço muito pequeno e a secretaria da escola é enorme. Proporemos à nossa dirigente regional de ensino que averigúe a possibilidade de remanejar os computadores e impressoras administrativos da secretaria para o local onde hoje está a biblioteca. Caso sejamos autorizados a fazer esta troca, penso ser muito coerente, pois a secretaria conta com apenas 03 funcionários e todo o seu aporte funcionará perfeitamente nos 11 metros quadrados onde está atualmente a biblioteca; e esta terá enfim uma ampla e confortável sala, pronta para receber um bom mobiliário, e melhor atender nossos usuários.

Promover reuniões com o objetivo de melhor capacitar nosso corpo docente e funcionários com vistas ao aperfeiçoamento dos serviços prestados e a um atendimento de excelência aos nossos clientes e usuários.

\section{Organização e gerência do empreendimento}

Ao refletirmos sobre o modo mais coerente possível para implementação do plano de empreendimento faz-se necessário a caracterização dos membros da equipe de gestão que estarão diretamente relacionados com esta proposta. Assim sendo ressaltamos: 
Diretora: Formação acadêmica constando curso de graduação na área de geografia e na área de história, licenciatura plena pela Associação Educacional de Jales; em pedagogia - administração escolar pela Universidade de Marília com licenciatura plena e também curso de pós-graduação lato sensu na área de geografia - Planejamento Territorial e Recuperação de Áreas Degradadas pela Universidade Federal de Mato grosso do Sul; além de diversos cursos de extensão cultural e atualização. Apresentando como experiência profissional cargo de professora de educação Básica II titular de cargo na rede pública, com experiência na rede particular e ocupando atualmente o cargo de diretor de escola.

Professora Coordenadora de Apoio à gestão: (PCAGP) Formação acadêmica consta licenciatura plena no curso de letras -UNESP - Campus - Assis/SP e licenciatura plena em pedagogia - Faculdades Integradas de Urubupungá- Pereira Barretos-SP possuindo como experiência profissional 12 anos como PEB II, um ano como diretora de escola, dois anos como vice-diretora e cinco anos como professora coordenadora.

Professora Coordenadora Pedagógica: (PC) Formação acadêmica consta licenciatura plena no curso de letras pela Faculdade de Filosofia Ciências e letras de Araçatuba-SP Unitoledo e licenciatura plena em pedagogia pelas Faculdades Integradas de Urubupungá - Pereira Barreto-SP. Ocupa o cargo de professor coordenador pedagógico com experiência profissional há 13 anos.

Professores Readaptados: Uma docente com licenciatura plena em ciências com habilitação em ciências físicas e biológicas e matemática pela faculdade de filosofia ciências e letras de Jales/SP ocupando o cargo de professor de educação básica II com experiência de 21 anos e outro com licenciatura plena em geografia sendo professor de educação básica II com experiência há 14 anos ambos na rede pública estadual de ensino.

Professora de Língua Portuguesa do Ensino Fundamental Regular: Licenciatura plena no curso de Letras pela faculdade de filosofia ciências e letras Araçatuba-SP ocupando o cargo de professor de educação básica Il com experiência de oito anos na rede pública estadual de ensino.

Professora de Língua portuguesa do Ensino Médio: Licenciatura plena no curso de Letras pela faculdade de filosofia ciências e letras Araçatuba-SP ocupando o cargo de professor de educação básica II com experiência de nove anos na rede pública estadual de ensino.

Professora de Leitura e produção de Textos: Licenciatura plena no curso de Letras pela faculdade de filosofia ciências e letras Araçatuba-SP, concluiu também curso de "Especialização" em metodologia do ensino e aprendizagem em língua portuguesa pela faculdade de educação São Luís de Jaboticabal-SP.

Exerce função atividade de professor de educação básica II na rede pública estadual de ensino com experiência há 19 anos.

Esta equipe escolar possui já há bastante tempo um perfil muito participativo de incentivo à leitura, de atuação em diversos concursos literários, redações, apresentações teatrais e também cultivam o hábito de anualmente editar um jornal da escola denominado "Noticiário Luiz Gama" edição muito bem aceita por toda a comunidade em que a unidade escolar se encontra inserida. Todos os acontecimentos esportivos, culturais, curiosidades de diferentes áreas de estudos e destaques da participação dos estudantes, docentes e funcionários nas mais diversas modalidades são veiculados na edição tipo tabloide e é realizada a distribuição na comunidade constituindo-se num meio de divulgação das atividades culturais/pedagógicas desencadeadas na escola.

O plano de empreendimento certamente se materializará com o envolvimento de todo o corpo docente sob a liderança da equipe gestora e daqueles que são especialistas da área de comunicação e expressão constituindo-se numa ação fortemente favorável à evolução intelectual de nossos usuários/clientes.

Para que nossas expectativas se concretizem da maneira que esperamos também é necessário que toda a equipe envolvida conheça a estrutura de gestão que vigorará desde a implantação e durante todo 0 processo de funcionamento da sala de leitura, pois, o comprometimento de todos é sempre de fundamental importância para que os objetivos previstos sejam de fato atingidos. 
Segue um organograma simplificado definindo a estrutura de gestão necessária para o funcionamento deste plano de empreendimento

\section{Gerir sala de leitura}

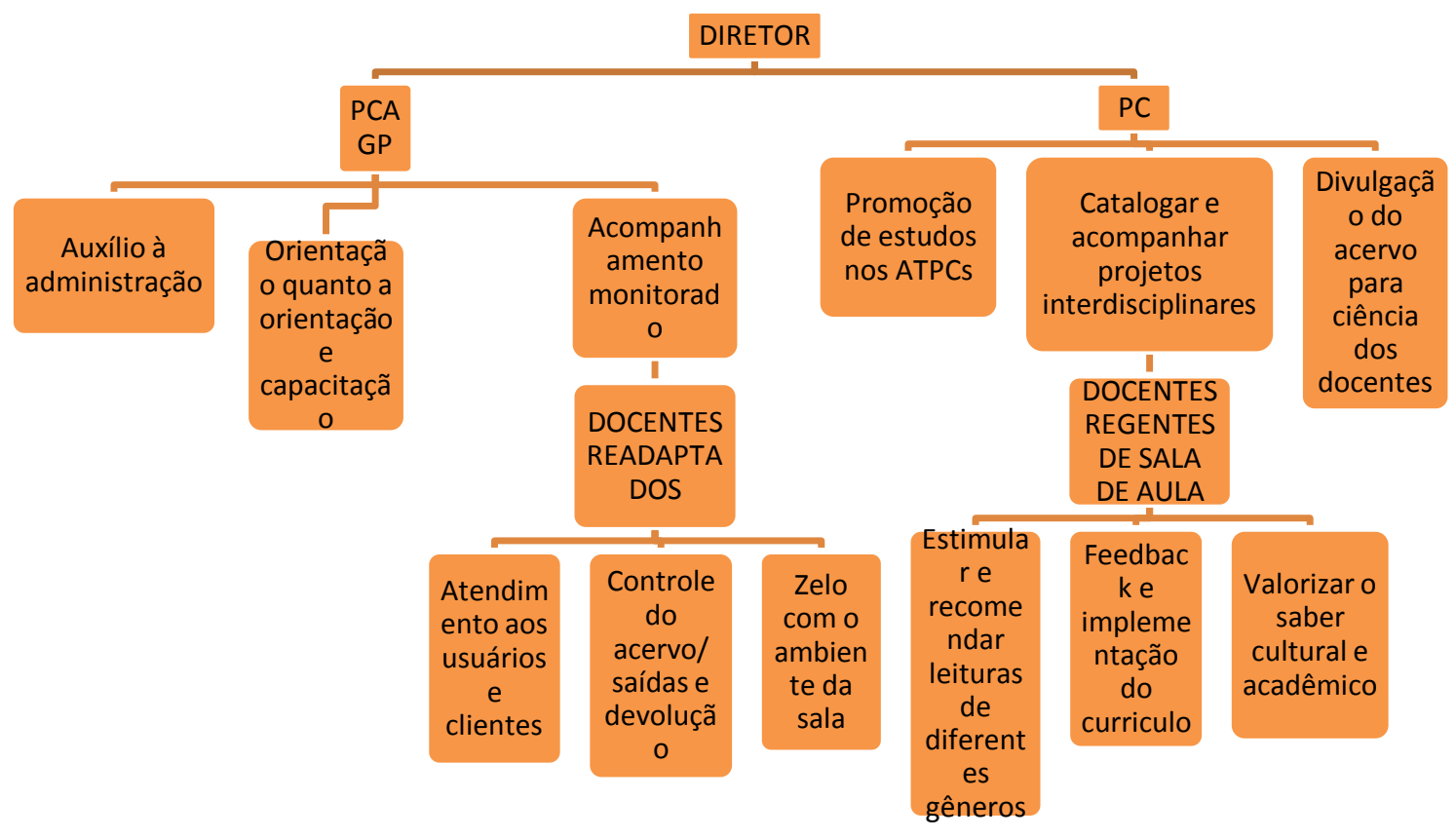

A atuação da direção jamais poderá perder de vistas que a escola é um local de formação dos cidadãos assim, o aluno há que ser sempre o ponto principal da instituição. Para que ocorra a boa estruturação do processo é importante que se considere a faixa etária e o foco de interesse dos leitores usuários; simultaneamente acompanhar o trabalho valorizando sempre os professores e proporcionando a capacitação dos mesmos em serviço utilizando para tal os A.T.P.Cs. (Aulas de trabalho pedagógico) que são semanais e possibilitam maior comprometimento de toda a equipe escolar, pois projetos que implementam leitura e letramento, mesmo estando sob a liderança dos especialistas na área de comunicação e expressão é sempre uma responsabilidade de todas as áreas do conhecimento.

A capacitação do corpo docente tende a fortalecer e conectar o empreendimento rumo aos objetivos almejados e a manifestação de reconhecimento da equipe gestora aos profissionais que promovem a evolução intelectual dos usuários e clientes constituem-se em ações dinamizadoras do processo.

\section{Plano financeiro}

Os investimentos iniciais necessários para a implantação da sala de leitura requerem a compra de mobiliário constituído por oito mesas preferencialmente redondas com seis cadeiras cada uma, sendo adequadas para acomodação dos alunos. Também as prateleiras com resistência suficiente para a guarda do acervo, uma impressora e um computador para bem se catalogar e controlar as entradas e saídas dos livros.

Considerando ainda a importância de se efetuar a reinstalação dos computadores e impressoras administrativos em outra sala da escola concretizando o deslocamento da secretaria sem ocorrer o prejuízo 


\section{Leitura e letramento}

dos serviços. Por se tratar de estimativa mantivemos os mesmos valores para os meses subsequentes, pois alterações dependerão dos rumos que a economia do país direcionar.

A tabela especificada a seguir demonstra uma possível previsão de investimentos.

Investimentos (despesas de capital)

\begin{tabular}{|l|l|l|l|}
\hline Item & Ano1 & Ano2 & Ano3 \\
\hline Adaptação de infraestrutura & $1.100,00$ & 0,00 & 0,00 \\
\hline Instalações de impressoras & & & \\
\hline Instalações Elétricas de computadores & 500,00 & 0,00 & 0,00 \\
\hline Material permanente & 600,00 & 0,00 & 0,00 \\
\hline 08 Mesas & $8.880,00$ & 0,00 & 0,00 \\
\hline 01 Computador & 480,00 & 0,00 & 0,00 \\
\hline 48 Cadeiras & $1.000,00$ & 0,00 & 0,00 \\
\hline 10 Armários tipo prateleiras & $2.400,00$ & 0,00 & 0,00 \\
\hline 01 Impressora & $3.000,00$ & 0,00 & 0,00 \\
\hline & $2.000,00$ & 0,00 & 0,00 \\
\hline & & & \\
\hline Total & & 0,00 & 0,00 \\
\hline
\end{tabular}

Tabela 9: Despesas de Capital

Nos anos posteriores não há previsão de despesas de capital, uma vez que, o zelo com o ambiente aliado à conscientização dos usuários certamente permitirá o bom uso desse espaço; o mais provável serão as despesas de consumo conforme consta na tabela abaixo, a qual aponta uma estimativa de investimentos referentes às despesas correntes que serão necessários com vistas ao bom andamento do projeto ao longo do tempo, não deixando de considerar que as alterações que se fizerem necessárias dependerão do andamento da economia do país, fato que, poderá ocasionar pequenas adequações pois nesse momento não temos previsões de reajustes.

\begin{tabular}{|c|c|c|c|c|}
\hline Material de Consumo & O item é mensal? & Valor mensal & Há reajuste? & $\%$ de reajuste anual \\
\hline Produtos de Limpeza & $\operatorname{sim}$ & 200,00 & Não & 0 \\
\hline Cartucho preto para impressora & $\operatorname{sim}$ & 280,00 & Não & 0 \\
\hline Cartucho colorido para impressora & sim & 380,00 & Não & 0 \\
\hline \multicolumn{5}{|l|}{ Total: $R \$ 860,00$} \\
\hline
\end{tabular}




\section{Emília dos Santos Soares}

\begin{tabular}{|l|l|l|l|l|l|}
\hline Passagens e Locomoção & O item é mensal? & Valor mensal & Há reajuste? & \% de reajuste anual \\
\hline Total & O item é mensal? & Valor mensal & Há reajuste? & $\%$ de reajuste anual \\
\hline Serviços de Terceiros & sim & 800,00 & Não & 0 \\
\hline Limpeza Terceirizada & & & \\
\hline Total: 1660,00 & & & \\
\hline \\
Total das Despesas Correntes: $R \$ 1660,00$
\end{tabular}

Tabela 10: Projeção das despesas correntes

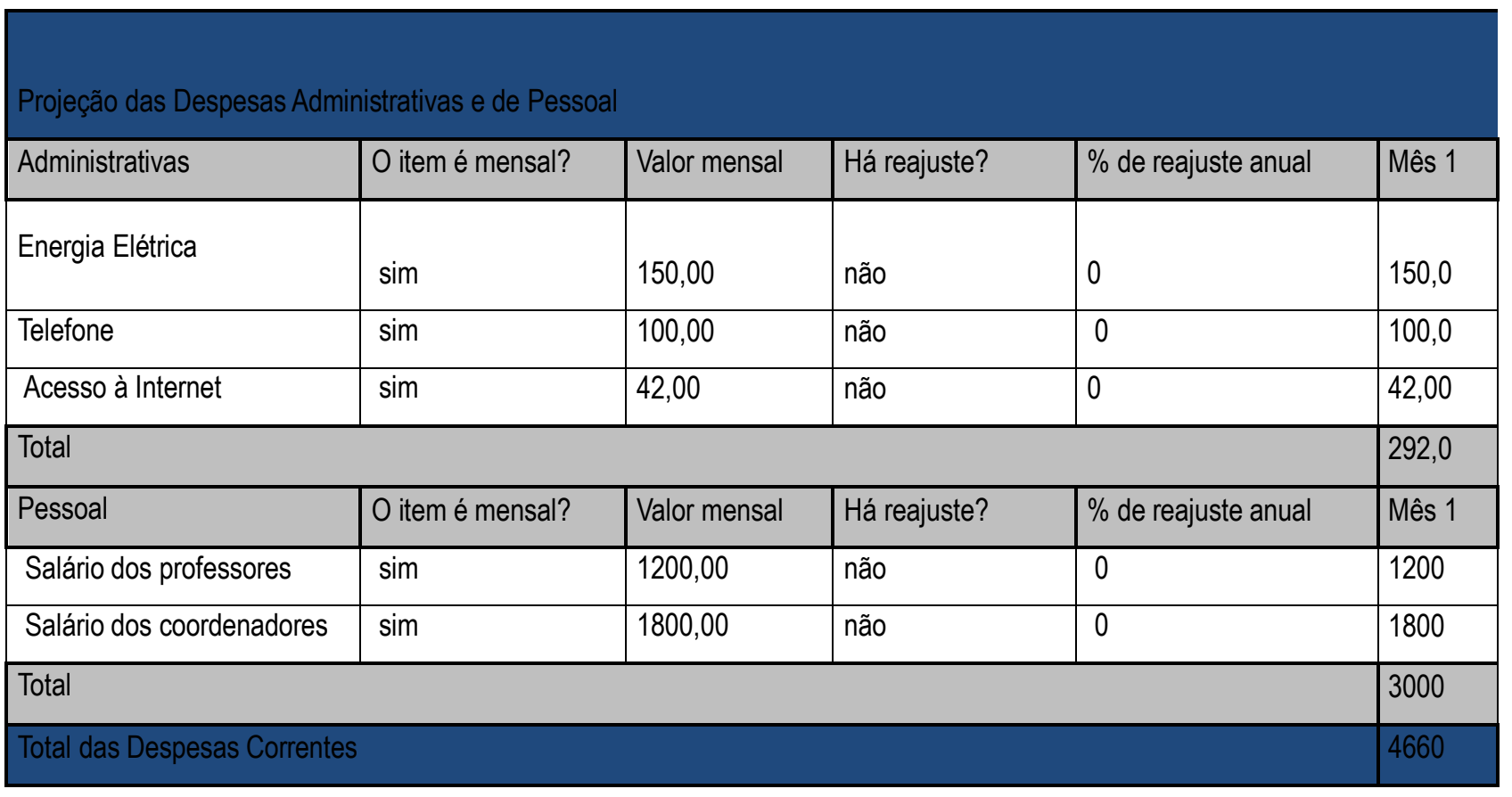

O plano de empreendimento elaborado com ciência e participação do corpo docente seguramente auxiliará a comunidade escolar podendo reverter em resultados muito positivos para todo 0 alunado, independentemente das séries, modalidades de ensino ou mesmo faixas etárias.

Os investimentos reais, no decorrer da implementação do plano poderão ser especificados em demonstrativos de fluxo de caixa possibilitando o acompanhamento mensal dos recursos financeiros necessários para a continuidade do projeto, porém podemos ressaltar que a sala de leitura após a implantação não constituirá em projeto de alto custo para a unidade de ensino, pois energia, telefone, despesas com salários dos profissionais, pessoal terceirizado que atuam na higienização dos espaços, material de limpeza, acesso à internet, já fazem parte da rotina escolar. A atenção nos anos subsequentes terá seu foco direcionado para a atualização e controle do acervo.

Trata-se, portanto de uma proposta perfeitamente viável do ponto de vista econômico e que certamente em muito favorecerá a qualidade dos serviços educacionais que prestamos com vistas à um aperfeiçoamento contínuo da aprendizagem dos estudantes que se encontram sob a responsabilidade desta equipe escolar.

Concluímos com a próxima tabela constando o cálculo de necessidade de recursos para a implementação real do plano, entendendo que a despesa com pessoal num primeiro olhar nos parece alta, porém se 


\section{Leitura e letramento}

considerarmos que todo o processo de ensino e aprendizagem sempre passa pela leitura dos mais diversos gêneros podemos compreender que diariamente, de uma forma ou de outra, o trabalho da equipe sempre se relaciona ao plano apresentado.

\begin{tabular}{|c|c|c|c|c|}
\hline \multicolumn{4}{|l|}{ Cálculo da Necessidade de Recursos } & \multirow[b]{2}{*}{ TOTAL } \\
\hline Item & ANOI & ANO 2 & ANO 3 & \\
\hline I. Total das Despesas Correntes & $19.920,00$ & $19.920,00$ & $19.92,00$ & $59.760,00$ \\
\hline Material de Consumo & $10.320,00$ & $10.320,00$ & $10.320,00$ & $30.960,00$ \\
\hline Passagens e Despesas com Locomoção & 0,00 & 0,00 & 0,00 & 0,00 \\
\hline Serviços de Terceiros & $9.600,00$ & $9.600,00$ & $9.600,00$ & $28.800,00$ \\
\hline II. Total de Despesas Administrativas & $3.504,00$ & $3.504,00$ & $3.504,00$ & $10.512,00$ \\
\hline III. Total de Despesas com Pessoal & $21.480,00$ & $21.480,00$ & $21.480,00$ & $64.440,00$ \\
\hline IV. Total de Despesas de Capital (investimentos) & $9.980,00$ & 0,00 & 0,00 & $9.980,00$ \\
\hline Necessidade de Recursos (I+||+|||+|V) & $54.884,00$ & $44.904,00$ & $44.904,00$ & $144.692,0$ \\
\hline Recursos Edital & $29.900,00$ & $19.920,00$ & $19.920,00$ & $69.740,00$ \\
\hline Recursos da Organização (contrapartida) & $24.984,00$ & $24.984,00$ & $24.984,00$ & $74.952,00$ \\
\hline
\end{tabular}

